\title{
Comparison of passive and semi-active suspension system by MATLAB SIMULINK for different road profiles
}

\author{
T. P. Phalke, A. C. Mitra \\ Mechanical Engineering, M.E.S. College of Engineering, Pune, S. P. Pune University, India
}

\begin{abstract}
Present trend is to design vehicles to provide maximum comfort to the driver and passenger in spite of the different road conditions. Suspension system is one of the part of vehicle which gives ride comfort. Suspension system plays major role in absorbing road vibrations and provides effective comfort to the diver as well as passenger. This paper presents performance comparison of passive and semi-active suspension system of a quarter car model for different vehicle velocities for half sine wave bump and then for different road profiles using MATLAB SIMULINK. In semi-active suspension system with Proportional-DerivativeIntegrator (PID) controller is developed which gives optimal and robust system by withstanding different road conditions and vehicle speeds to increase ride comfort
\end{abstract}

Keywords - PID controller, Passive suspension, Quarter car, semi-active suspension, MATLAB/SIMULINK.

\section{INTRODUCTION}

Suspension system absorbs major part of the vibrations produced from road surface and transfers little to passenger seat. As human has a tolerance to sustain acceleration at various excitation frequencies that vary as the road profile varies. Customer comfort is very important concern in the vehicle. Hence design of suspension system is challenging task for suspension design engineers. There are basically three types of suspension systems passive, semi-active and active suspension system. Passive and semi-active suspension systems are developed and analyzed for their performance in this paper.

Passive suspension system consists of spring and damper. Damper acts as an energy dissipating element while spring as an energy-storing element. Since these two elements do not add energy to the system this kind of suspension systems are called passive [1]. Parameters are generally fixed in passive suspension system, being chosen to achieve a certain level of compromise between road handling, load carrying and ride comfort [2]. Problem in case of passive suspension system is that heavily designed damper will transfer a lot of road input or throwing the car on unevenness of the road while in case of lightly designed damper suspension it will reduce the stability of vehicle while taking turns or changing lane or it may swing the car. Performance of suspension system depends upon road profiles [3]. In passive suspension system the ride comfort decreases with increase in spring stiffness, i.e. good ride comfort for soft spring and bad ride comfort for hard spring [4].

In Semi-active suspension system spring element is retained, but the damper is replaced with a controllable damper which requires small amount of external energy [5]. In semi-active suspension system force actuator is used in controller which control road irregularities and increase comfort level. It works in closed looped control system. The advantage of semi-active suspension system improves ride comfort than active suspension system with less amount of energy [1]. T. Ram Mohan Rao, et al. [1] and Rijumon, Murtaza, et al. [6] worked on skyhook control semi active suspension system. It was observed that skyhook control can achieve more reduction of resonant peak of the body mass than that of passive suspension. Dankan V Gowda et al. [7] worked on suspension with PID controller. Omid Ghasemalizadeh et al. [8], investigated control methodologies with the application of acceleration driven damper, power driven damper and $\mathrm{H} \infty$ Robust Control. Amit A. Hingane, et al. [9], worked on Bingham model for MR damper which is fluid based.

This paper represents work on passive and semi-active quarter car suspension system. Quarter car model is used because it gives the qualitatively correct information, especially for ride and handling studies. Simple model provides more exhaustive, accurate and comprehensive studies with more involved dynamical car models [10]. Quarter models are made in MATLAB SIMULINK. In semi-active suspension system Proportional Integral Differential Controller (PID) technique used. PID is self-tuning device according to road irregularities. It tunes P, I and D value and gives improved ride comfort than passive suspension system. Passive and semiactive models are developed in MATLAB and their performance is analyzed for different road input on sprung mass displacement. 
Comparison of passive and semi-active suspension system by MAYTLAB/SIMULINK for different road profile

\section{MATHEMATICAL MODEL OF PASSIVE AND SEMI-ACTIVE SUSPENSION SYSTEM}

Passive vibration control involves an inherent compromise between low-frequency and high-frequency vibration isolation while a semi-active suspension requires much less power, less complex, more reliable and can provide considerable improvements in vehicle ride quality [1]. 2-Degree of freedom (DOF) quarter car model diagrams of passive and semi-active suspension are as shown in Fig. 1 and Fig. 2 respectively.

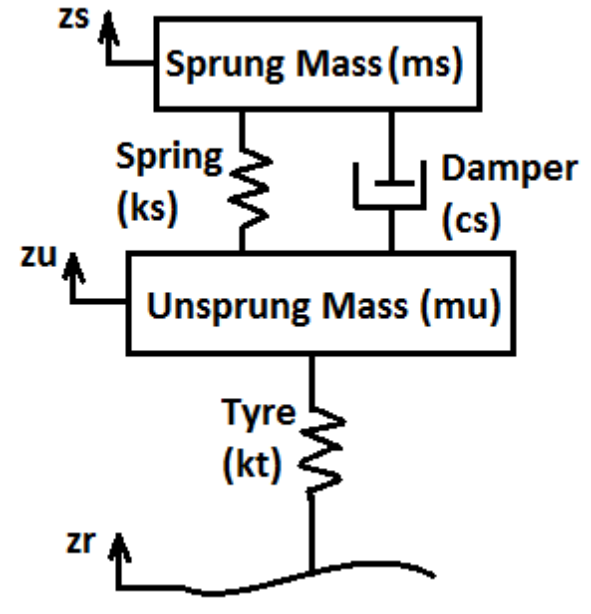

Fig. 1 Quarter car diagram of Passive suspension

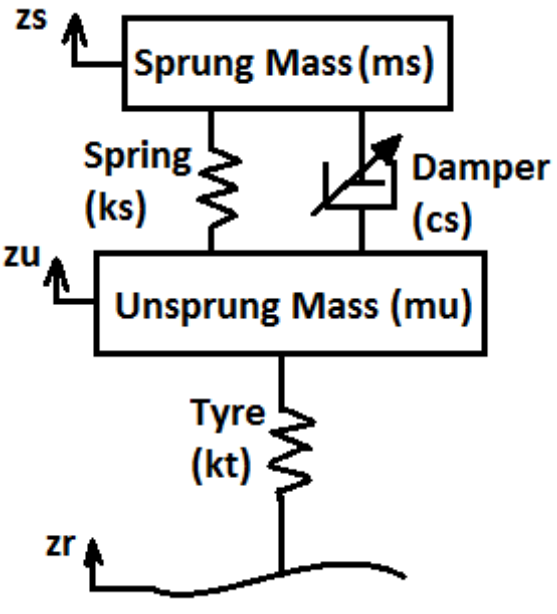

Fig. 2 Quarter car diagram of semi-active suspension

Fig. 1 and 2 show that suspension system is converted into spring and damper where $m s$ and mu are sprung and unsprung mass respectively. $k s, c s$, $k t$ are sprung mass stiffness, sprung mass damper and tire stiffness respectively. $z s, z u$ and $z r$ represent displacement of sprung mass, unsprung mass and road respectively. According to Newton's second law differential equations of motion can be written in standard form as follows:

$$
\begin{aligned}
& m s \times \ddot{z} s+c s \times(\dot{z} s-\dot{z} u)+k s \times(z s-z u)+m s \times g=0 \\
& m u \times \ddot{z} u-c s \times(\dot{z} s-\dot{z} u)-k s \times(z s-z u)+k t(z u-z r)+m u \times g=0
\end{aligned}
$$

From equations (1) and (2) mathematical model of passive and semi-active suspension system is made in MATLAB SIMULINK shown in Fig. 3 and 4. Aim of this work is to compare passive and semi-active suspension system. Comparative SIMULINK model of passive and semi-active suspension system is as shown in Fig. 5.

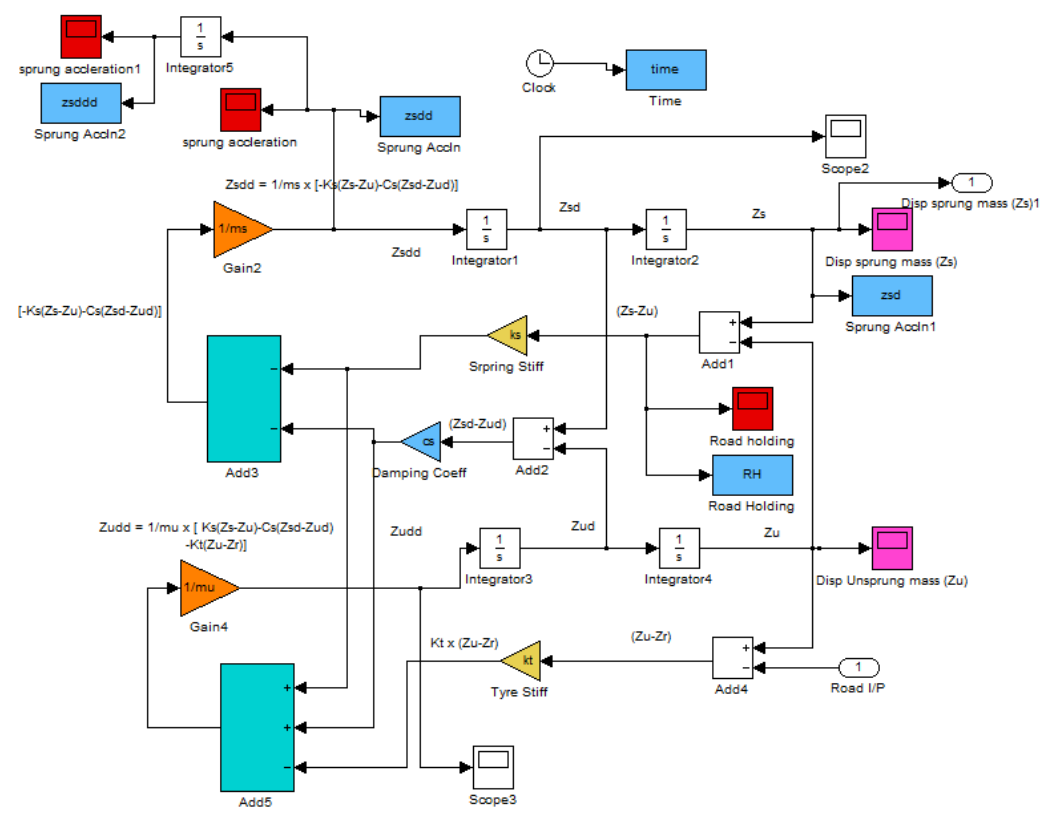

Fig. 3 Quarter car passive suspension model

$5^{\text {th }}$ National Conference RDME 2016, 10-1 $1^{\text {th }}$ March 2016. 


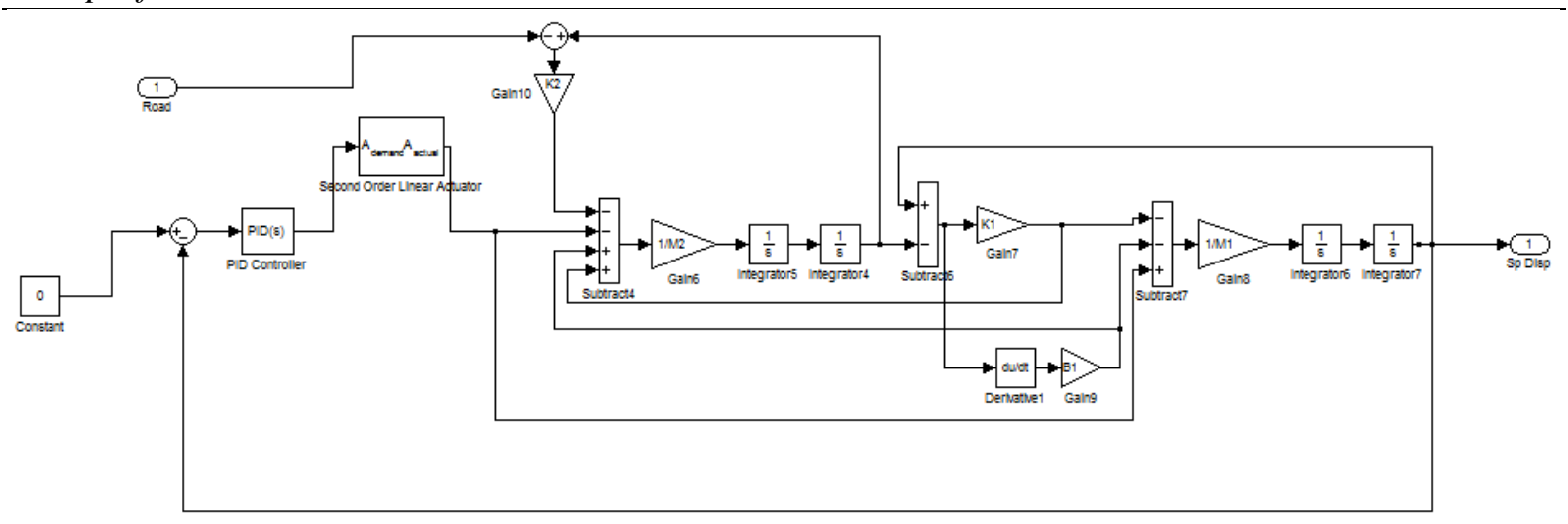

Fig. 4 Quarter car semiactive suspension model

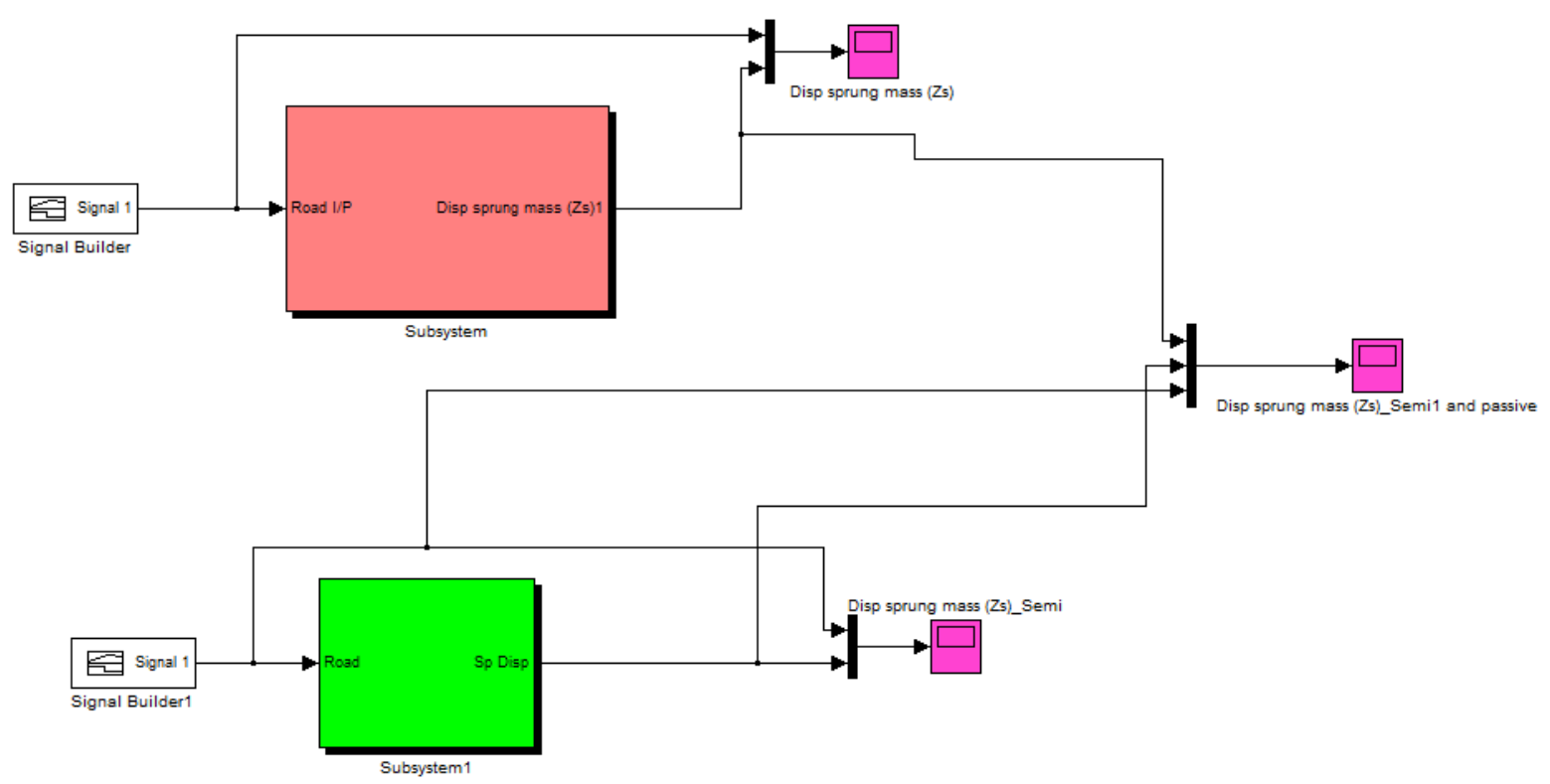

Fig. 5 Passive and Semi-active SIMULINK model

\subsection{PID control method}

PID basically works on principle of closed loop control system.

In which ' $\mathrm{P}$ ' stands for proportional: In proportional control output signal will be obtained by multiplying the current error signal with gain (kp).

' $I$ ' stands for integral: the integral sign is the sum of all the instantaneous values that the signal has been from whenever you started counting until u stop counting. When integral term adds to proportional term accelerates the movement of the process towards set-point and eliminates the residual steady state error that occurs with a proportional controller.

' $\mathrm{D}$ ' stands for derivative: The derivative term slows the rate of change of the controller output and this effect is most noticeable close to the controller set-point. When these all three are together it is called as PID controller. Fig. 6 shows PID controller used in semi-active suspension system. 
Comparison of passive and semi-active suspension system by MAYTLAB/SIMULINK for different road profile

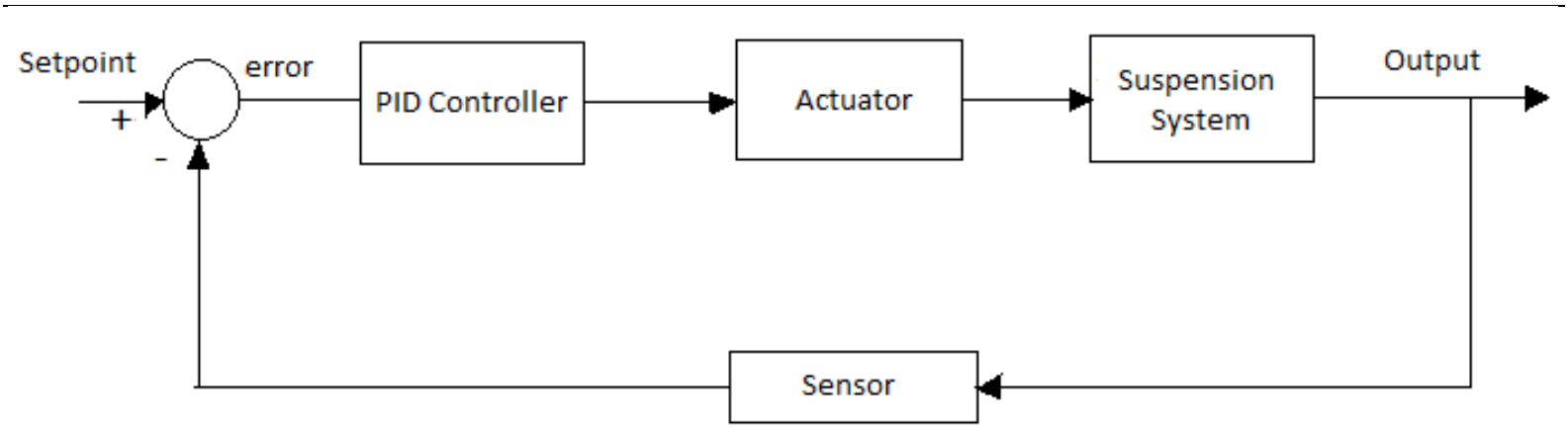

Fig. 6 Block diagram of suspension system using PID controller

As PID works on closed loop system principle process gets repeated till the output is reached equal to set-point.

To simulate model of passive and semi-active suspension system Table 1 shows input values.

TABLE 1. Input values for SIMULINK analysis [4]

\begin{tabular}{|c|c|}
\hline Parameters & Values \\
\hline $\mathrm{Ms}$ & $290 \mathrm{~kg}$ \\
\hline $\mathrm{Mu}$ & $59 \mathrm{~kg}$ \\
\hline $\mathrm{Ks}$ & $16182 \mathrm{~N} / \mathrm{m}$ \\
\hline $\mathrm{Cs}$ & $1000 \mathrm{Ns} / \mathrm{m}$ \\
\hline $\mathrm{Kt}$ & $190000 \mathrm{~N} / \mathrm{m}$ \\
\hline $\mathrm{a}$ & $0.05 \mathrm{~m}$ \\
\hline $\mathrm{h}$ & $0.1 \mathrm{~m}$ \\
\hline $\mathrm{V}$ & $20-80 \mathrm{kmph}$ \\
\hline
\end{tabular}

III. RESULTS AND DISCUSSION

Developed mathematical models for quarter car suspension are simulated in MATLAB SIMULINK software considering vehicle velocity range $20-80 \mathrm{kmph}$ for half sine bump with height of bump $0.1 \mathrm{~m}$. Observed effect of $20 \mathrm{kmph}, 40 \mathrm{kmph}, 60 \mathrm{kmph}$ and $80 \mathrm{kmph}$ vehicle velocity on sprung mass displacement in the form of graph are as shown in Fig. 7-10.

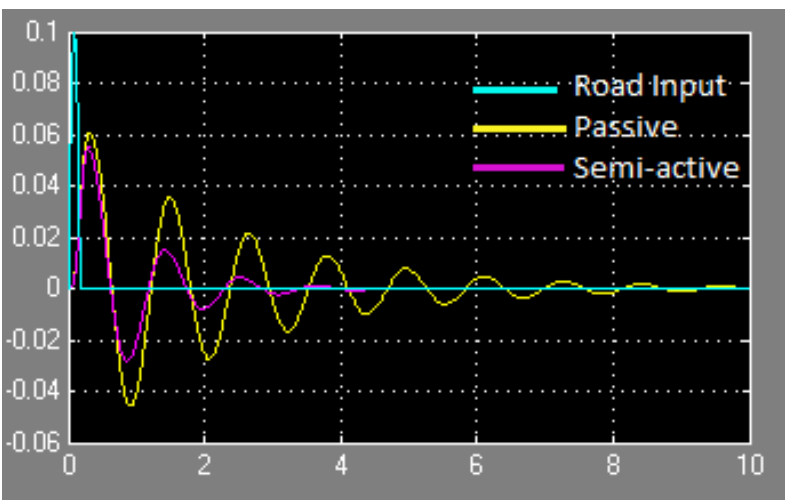

Fig. 7 Effect for 20 kmph velocity

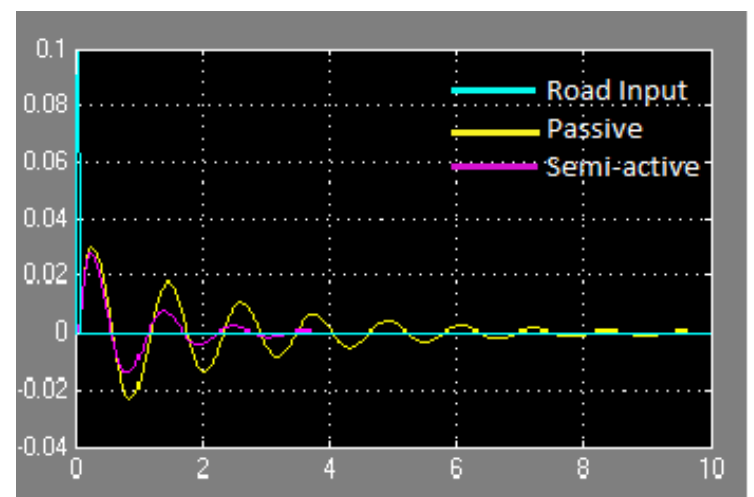

Fig. 8 Effect for $40 \mathrm{kmph}$ velocity 
Comparison of passive and semi-active suspension system by MAYTLAB/SIMULINK for different road profile

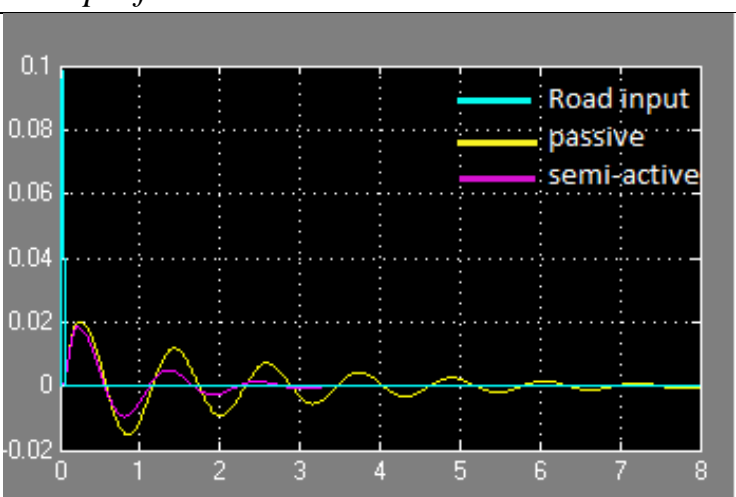

Fig. 9 Effect for $60 \mathrm{kmph}$ velocity

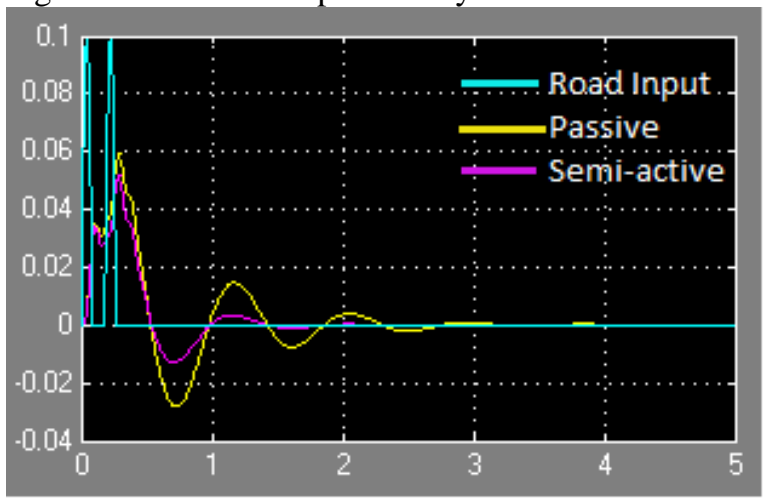

Fig. 11 For double sine wave bump displacement of sprung mass

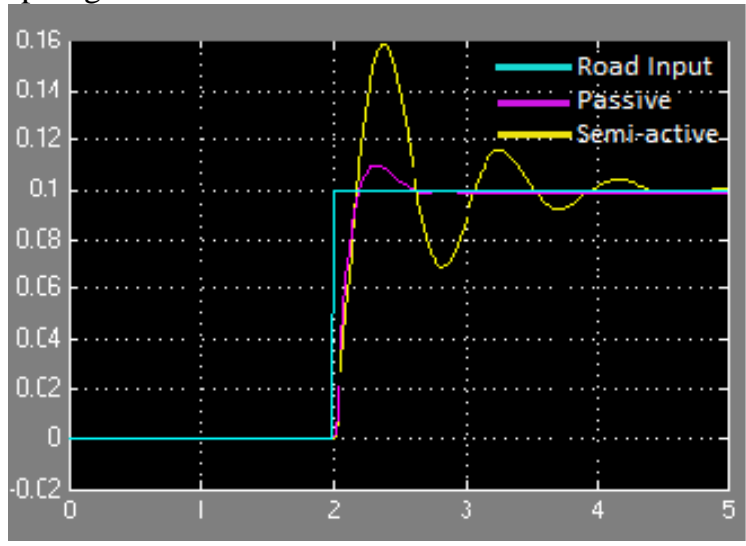

Fig. 13 For step bump displacement of sprung mass

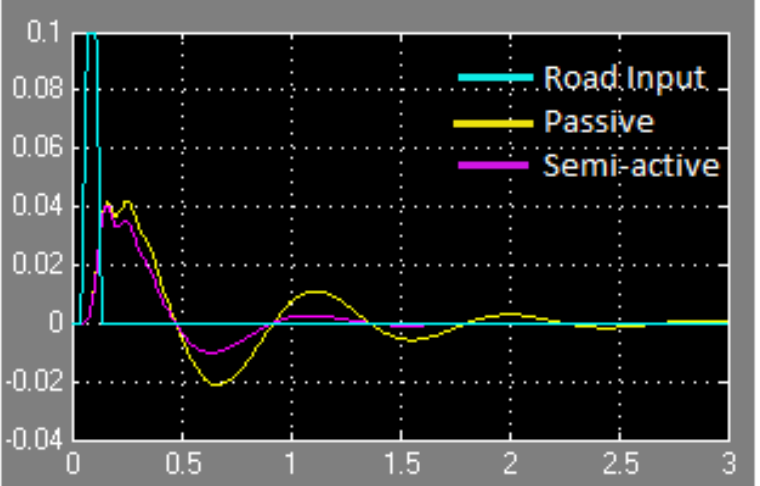

Fig. 10 Effect for $80 \mathrm{kmph}$ velocity

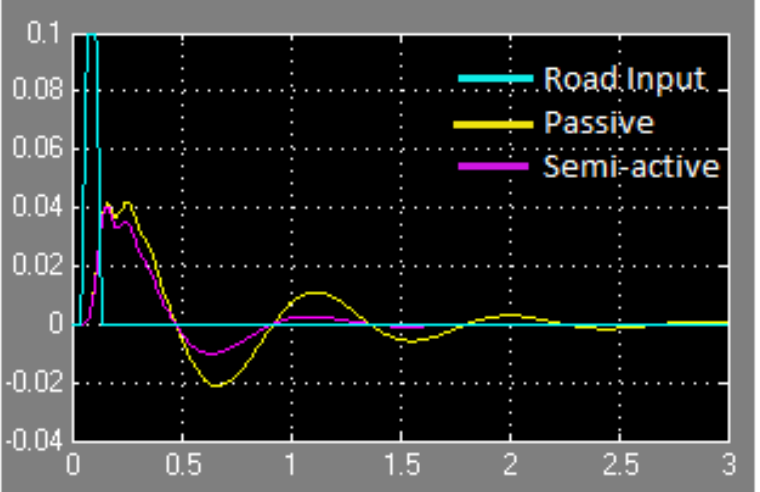

Fig.12 For trapezoidal bump displacement of sprung mass

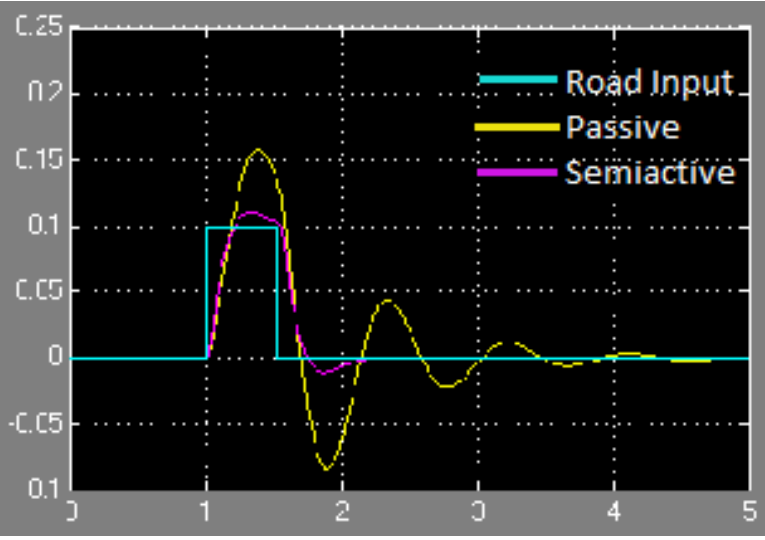

Fig. 14 For square bump displacement of sprung mass

From Fig. 7-10 it is concluded that with velocity change results into change in peak amplitude and settling time. Considering the variations in peak amplitude and settling time with velocity, $40 \mathrm{kmph}$ velocity is selected for further performance analysis.

By using velocity $40 \mathrm{kmph}$ different road profiles i.e. double sine wave, trapezoidal, step and square bump with height of bump $0.1 \mathrm{~m}$ are analyzed by MATLAB/SIMULINK it gives results in form of graph as shown in Fig. 11-14.

It is observed that improved performance is obtained by semi-active suspension system with PID controller than passive suspension system. From Fig. 11 for double sine bump peak amplitude for passive and semi-active suspension system are $0.06,0.054 \mathrm{~mm}$ and settling time $3 \mathrm{sec}, 1.8 \mathrm{sec}$ respectively. Similarly, from Fig. 12 for trapezoidal bump peak amplitude for passive and semi-active suspension system are 0.042, $0.04 \mathrm{~mm}$ and settling time $2.6 \mathrm{sec}, 1.5 \mathrm{sec}$ respectively. From Fig. 13 for step bump peak amplitude for passive and semiactive suspension system are $0.16,0.11 \mathrm{~mm}$ and settling time $4.3 \mathrm{sec}, 2.8 \mathrm{sec}$ respectively. From Fig. 14 for square bump peak amplitude for passive and semi-active suspension system are $0.155,0.11 \mathrm{~mm}$ and settling time $4.3 \mathrm{sec}, 2.2 \mathrm{sec}$ respectively. 
TABLE 2. Settling time improvement in percentage

\begin{tabular}{|c|c|c|c|}
\hline Input profile & $\begin{array}{c}\text { Settling time of Passive } \\
\text { suspension } \\
\text { system }\end{array}$ & $\begin{array}{c}\text { Settling time of semi- } \\
\text { active suspension system }\end{array}$ & $\begin{array}{c}\text { Percentage } \\
\text { improvement (\%) }\end{array}$ \\
\hline Half sine bump & 8.2 & 4 & 51 \\
\hline Double half sine bump & 3 & 1.8 & 40 \\
\hline Trapezoidal bump & 2.6 & 1.5 & 42.3 \\
\hline Step bump & 4.3 & 2.8 & 34.9 \\
\hline Square bump & 4.3 & 2.2 & 48.8 \\
\hline
\end{tabular}

\section{CONCLUSION}

Quarter car passive and semi-active suspension system models are developed and comparative performance analysis is carried out using MATLAB SIMULINK. Results show that using PID controller in semi-active suspension system improves performance much better than the passive suspension system. PID controller can be designed for good ride comfort, small amplitude value for suspension travel and reduced settling time to reach the steady state fast. Hence by replacing passive suspension by semi-active suspension efficient ride comfort as well as road holding can be achieved under different road profiles and vehicle velocities. Percentage improvement in settling time for half sine bump, double sine bump, trapezoidal bump, step bump and square bump is $51 \%, 40 \%, 42.3 \%, 34.9 \%$ and $48.8 \%$ respectively.

\section{REFERENCES}

[1] T. R. Mohan Rao, G. V. Rao, K. S. Rao \& A. Purushottam, Analysis of passive and semi active controlled suspension systems for ride comfort in an omnibus passing over a speed bump, IJRRAS 5 (1) October 2010.

[2] D. V. Gowda, S. Chakrasali, Comparative Analysis of Passive and Semi-Active Suspension System for Quarter Car Model using PID Controller, Association of Computer Electronics and Electrical Engineers, 2014.

[3] A. Agharkakli, G. S. Sabet, A. Barouz, Simulation and Analysis of Passive and Active Suspension System Using Quarter Car Model for Different Road Profile, International Journal of Engineering Trends and Technology, 3(5), 2012

[4] A. C. Mitra, N. Benerjee, Ride comfort and Vehicle handling of Quarter Car Model Using SIMULINK and Bond Graph, Proceedings of the 1st International and 16th National Conference on Machines and Mechanisms (iNaCoMM2013), IIT Roorkee, India, Dec 18-20 2013

[5] R. N. Sandage, P. M. Patil, S. A. Patil, Simulation Analysis of 2dof Quarter Car Semi- Active Suspension System to Improve Ride Comfort - A Review, International Journal of Application or Innovation in Engineering \& Management (IJAIEM), 2 (12),2013.

[6] K. Rijumon, M. A. Murtaza, A. Krishnan, Comparison of passive and semi-active suspension system, International Journal of Innovative Research in Science, Engineering and Technology, 2(6),2013.

[7] D. V. Gowda and S. Chakrasali, Comparative Analysis of Passive and Semi-Active Suspension System for Quarter Car Model using PID Controller, Association of Computer Electronics and Electrical Engineers, 2014.

[8] O. Ghasemalizadeh1, S. Taheri, A. Singh, J. Goryca, Semi-active suspension control using modern methodology : a comprehensive comparison study, NDIA ground vehicle systems engineering and technology symposium modeling \& simulation, testing and validation (mstv) technical session august 12-14, 2014 - novi, Michigan

[9] A. A. Hingane, S. H. Sawant, S. P. Chavan, A. P. Shah, Analysis of Semi active Suspension System with Bingham Model Subjected to Random Road Excitation Using MATLAB/Simulink, IOSR Journal of Mechanical and Civil Engineering (IOSR-JMCE),,01-06.

[10] G. Verros, s. Natsiavas, G. Stepan, Control and dynamics of quarter-car models with dual-rate damping, Journal of Vibration and Control, 6, 2000, 1045-1063. 